\title{
Hydrogen Peroxide Generation at LiquidlLiquid Interface under Conditions Unfavorable for Proton Transfer from Aqueous to Organic Phase
}

\author{
Justyna Jedraszko, ${ }^{\dagger}$ Wojciech Nogala, ${ }^{\dagger}$ Wojciech Adamiak, $^{\dagger}$ Ewa Rozniecka, $^{\dagger}$ \\ Iwona Lubarska-Radziejewska, ${ }^{\dagger}$ Hubert H. Girault, ${ }^{\ddagger}$ and Marcin Opallo*, ${ }^{\dagger}$ \\ ${ }^{\dagger}$ Institute of Physical Chemistry, Polish Academy of Sciences, Warsaw 01-224, Poland \\ ${ }^{\ddagger}$ LEPA, Ecole Polytechnique Federale de Lausanne, Lausanne CH-1015, Switzerland
}

Supporting Information

ABSTRACT: The charge transfer processes across the interface between two immiscible electrolyte solutions (ITIES) can be employed for energy storage and conversion, solvent extraction, or sensing or in life sciences. Among them are catalytic reactions, which have only been recently studied. Here $\mathrm{H}_{2} \mathrm{O}_{2}$ generation is studied with decamethylferrocene (DMFc) as electron donor at the interface between tetrahexylammonium perchlorate solution in 1,2dichloroethane (1,2-DCE) and aqueous $\mathrm{HClO}_{4}$. These conditions are unfavorable for proton transfer across ITIES because of positive Galvani potential difference. Voltammetry with 1,2DCE droplet modified electrode shows that DMFc oxidation is accompanied by $\mathrm{ClO}_{4}^{-}$ insertion into the organic phase. The reaction progress was followed by UV-vis spectroscopy, voltammetry, and scanning electrochemical microscopy (SECM). In the first and last method, horseradish peroxidase was used as catalyst. It is concluded that $\mathrm{O}_{2}$ is reduced to $\mathrm{H}_{2} \mathrm{O}_{2}$ at the liquidlliquid interface not only under conditions when proton transfer to organic phase is strongly favored, namely, when Galvani potential difference is

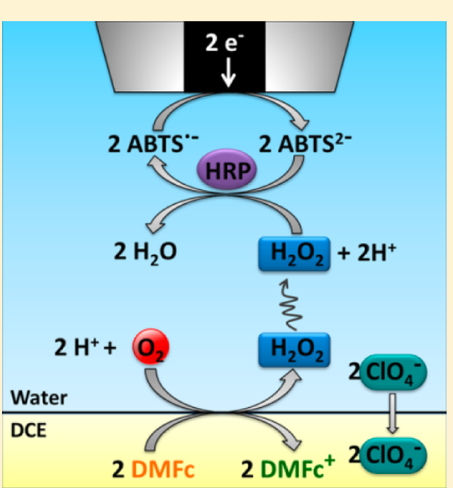
negative (Angew. Chem., Int. Ed. 2008, 47, 4675-4678).

\section{INTRODUCTION}

Catalysis at interfaces between two immiscible electrolyte solutions (ITIES) has recently gained increased interest. ${ }^{1}$ This is because at soft interfaces a wide range of charge transfer processes such as simple or assisted ion transfer, electron transfer, or proton assisted electron transfer can be driven by polarization of ITIES, namely, Galvani potential difference. It can be generated by applying voltage across ITIES or more practically, by appropriate selection of electrolytes having a common ion in both phases. ${ }^{2}$ In a typical case, the substrates and the products are present in one phase, whereas the electron donor is present in the other one. ${ }^{3}$

Oxygen reduction to $\mathrm{H}_{2} \mathrm{O}_{2}$ is the most frequently studied catalytic reaction at soft interfaces. ${ }^{4}$ It is worth mentioning that hydrogen peroxide is an important product because of its consumption by industry on the level of 2.2 million tons per annum. ${ }^{5}$ The construction of fuel cell generating hydrogen peroxide is also an interesting concept from the point of view of its economy. ${ }^{6}$ Metal porphyrins, tetrathiafulvalene, tetrachlorohydroquinone, and ferrocene derivatives such as decamethylferrocene $(\mathrm{DMFc})$ or 1,2-diferrocenylethane were used as electron donors in oxygen reduction to hydrogen peroxide at polarized 1,2-dichloroethane (DCE) Iwater (W) interfaces. ${ }^{1,4,6-13}$ This reaction was proposed to involve proton transfer from aqueous $(\mathrm{W})$ to organic phase $(\mathrm{O})$ followed by $\mathrm{O}_{2}$ reduction to $\mathrm{H}_{2} \mathrm{O}_{2}$ formed in the aqueous phase with both oxidized and reduced forms of $\mathrm{DMFc}$ remaining in organic phase: ${ }^{1}$

$$
\mathrm{O}_{2(\mathrm{~W})}+2 \mathrm{DMFc}_{(\mathrm{O})}+2 \mathrm{H}_{(\mathrm{W})}^{+} \rightarrow \mathrm{H}_{2} \mathrm{O}_{2(\mathrm{~W})}+2 \mathrm{DMFc}_{(\mathrm{O})}^{+}
$$

DMFc molecules serve as a source of electrons and formation of their protonated form, $\mathrm{DMFCH}^{+}$, is the first step of this reaction. In earlier reports, this reaction was carried out under conditions favorable for proton transfer. ${ }^{4}$ This was achieved by application of extremely hydrophobic electrolyte, that is, bis(triphenylphosphoranylidene)ammonium tetrakis(pentafluorophenyl)borate in the organic phase and the hydrophilic lithium salt of the same anion in the aqueous phase to keep the Galvani potential difference $\left(\Delta_{\mathrm{W}}^{\mathrm{DCE}} \phi\right)$ lower than the proton transfer standard potential $\left(\Delta_{\mathrm{W}}^{\mathrm{DCE}} \phi_{\mathrm{H}^{+}}^{\circ}\right)$.

Here we show that $\mathrm{H}_{2} \mathrm{O}_{2}$ is generated from oxygen at polarized DCEIW interface also when proton transfer is unfavorable, that is, when $\Delta_{\mathrm{W}}^{\mathrm{DCE}} \phi$ is higher than $\Delta_{\mathrm{W}}^{\mathrm{DCE}} \phi_{\mathrm{H}^{+}}^{\circ}=$ $-0.55 \mathrm{~V} .{ }^{14}$ This is achieved with $\mathrm{ClO}_{4}^{-}$anions present in both phases. Taking into account $\Delta_{\mathrm{W}}^{\mathrm{DCE}} \phi_{\mathrm{ClO}_{4}{ }^{-}}^{\circ}=0.177 \mathrm{~V}^{15}$ and assuming the same activities of $\mathrm{ClO}_{4}{ }^{-}$in both phases, a general expression for Galvani potential difference,

Received: June 28, 2013

Revised: September 6, 2013

Published: September 10, 2013 


$$
\Delta_{\mathrm{W}}^{\mathrm{DCE}} \phi=\Delta_{\mathrm{W}}^{\mathrm{DCE}} \phi_{\mathrm{ClO}_{4}^{-}}^{0}+\frac{R T}{F} \ln \frac{a_{\mathrm{ClO}_{4}^{-}}(\mathrm{DCE})}{a_{\mathrm{Cl}_{4}^{-}}(\mathrm{W})}
$$

can be rewritten to give

$$
\Delta_{\mathrm{W}}^{\mathrm{DCE}} \phi=\Delta_{\mathrm{W}}^{\mathrm{DCE}} \phi_{\mathrm{ClO}_{4}^{-}}^{0}=0.177 \mathrm{~V}
$$

Clearly, under these conditions, $\Delta_{\mathrm{W}}^{\mathrm{DCE}} \phi$ is higher than $\Delta_{\mathrm{W}}^{\mathrm{DCE}} \phi_{\mathrm{H}^{+}}^{0}$ and proton transfer is unfavorable.

This report starts from voltammetric experiments with glassy carbon (GC) electrode covered with droplet of supported organic phase containing DMFc immersed in a wide range of aqueous electrolytes. ${ }^{16}$ This was done to estimate to what extent generation of $\mathrm{DMFc}^{+}$in the organic phase (reaction 1) results in expulsion of electron donor from the organic phase or anion insertion into the organic phase. Generation of $\mathrm{H}_{2} \mathrm{O}_{2}$ under conditions unfavorable for proton transfer was monitored by change of solution color ${ }^{17,18}$ or scanning electrochemical microscopy (SECM). The latter methods allows detection of electroactive molecules close to ITIES. ${ }^{19,20}$ Here, for the first time SECM enzymatic detection of $\mathrm{H}_{2} \mathrm{O}_{2}$ at the liquidlliquid interface with horseradish peroxidase (HRP) is reported. Here, the ability of HRP to catalyze two-electron hydrogen peroxide reduction to water ${ }^{21,22}$ with 2,2'-azino-bis-3-ethylbenzothiazoline-sulfonate $\left(\mathrm{ABTS}^{2-}\right)^{17,23-25}$ as electron donor is employed, because the oxidized form of the mediator can be easily detected at SECM tip. ${ }^{26}$ Finally, the possibility of regeneration of DMFc electron donor close to ITIES was studied with two microelectrodes facing each other with ITIES in between.

\section{EXPERIMENTAL METHODS}

Chemicals. DMFc (99\%) was obtained from ABCR. Tetrahexylammonium perchlorate (THxAP) was prepared by metathesis of tetrahexylammonium chloride (Fluka, 96\%) and $\mathrm{HClO}_{4}$ (Sigma-Aldrich, 70\%) following the procedure described for tetrabutylammonium perchlorate ${ }^{27}$ and recrystallized twice from a mixture of ethyl acetate and ethanol. $\mathrm{NaClO}_{4}$ was purchased from Fluka. ABTS $\left(\mathrm{NH}_{4}\right)_{2}$, HRP type VI-A, $\mathrm{NaCl}$, and DCE were from Sigma-Aldrich. $\mathrm{NaH}_{2} \mathrm{PO}_{4}$ and $\mathrm{NaOH}(\mathrm{POCH})$ were used for $0.1 \mathrm{~mol} \mathrm{dm}^{-3}$ phosphate buffer $(\mathrm{pH} 7)$ preparation. All aqueous solutions were prepared with demineralized and filtered water from ELIX system (Millipore). Argon gas was from Multax.

Apparatus and Procedures. Cyclic voltammetry and square wave voltammetry (SWV) with GC modified with the organic droplet were performed with Autolab (Eco Chemie) electrochemical workstation. Interfacial reaction was performed through $24 \mathrm{~h}$ with stirring. The volumes of DCE and W phases were $2 \mathrm{~mL}$ each, and internal diameter of the flasks was $13 \mathrm{~mm}$. Pt disk microelectrode (10 $\mu \mathrm{m}$ diameter, $\mathrm{nLab})$ or GC $(2 \mathrm{~mm}$ diameter, nLab) were used as working electrodes. Pt wire was used as counter electrode; $\mathrm{Ag}$ wire or $\mathrm{Ag} / \mathrm{AgCl} / \mathrm{KCl}$ were used as reference electrodes.

SECM measurements were carried out with CHI900B SECM workstation ( $\mathrm{CH}$ Instruments). Pt microelectrodes for SECM experiments were made by sealing a Pt wire $(25 \mu \mathrm{m}$ diameter, Goodfellow, England, or $100 \mu \mathrm{m}$ diameter, Mennica Polska, Poland) using PC-10 micropipet puller (Narishige) into borosilicate glass capillaries and polished. These microelectrodes were used as working electrodes in aqueous and organic solution, respectively. The microelectrode immersed in organic phase was fixed upward at the bottom of the cell. Pt wire and $\mathrm{Ag} / \mathrm{AgCl} / \mathrm{KCl}$ were counter and reference electrodes respectively, and were immersed in the aqueous phase. The Agl $\mathrm{AgCl} / \mathrm{KCl}$ electrode had an additional glass compartment with a frit filled with $0.1 \mathrm{~mol} \mathrm{dm}{ }^{-3}$ aqueous $\mathrm{HClO}_{4}$ perchloric acid solution to prevent traces of $\mathrm{Cl}^{-}$anions from transferring to the cell. This is important, because of their possible oxidation on the $\mathrm{Pt}$ at potentials above $1.1 \mathrm{~V}$ vs $\mathrm{Ag} / \mathrm{AgCl} / \mathrm{KCl}$. The $\mathrm{Pt}$ microelectrode in the aqueous phase served as SECM tip, and its position was controlled by stepper motors in the $X, Y$, and $Z$ directions. A specwell $10 \times 30$ monocular precision magnifier was used to confirm the distance between two electrodes. All working electrodes were polished with $1,0.3$, and $0.05 \mu \mathrm{m}$ alumina and sonicated in demineralized water. Argon was bubbling through the two liquid phases for $15 \mathrm{~min}$ before measurements, and during the measurement, it was passed above the solution. UV-vis spectra were recorded by Evolution 300 UV-vis spectrophotometer, Thermo Scientific. All measurements were performed at room temperature $(22 \pm 2$ $\left.{ }^{\circ} \mathrm{C}\right)$.

\section{RESULTS AND DISCUSSION}

Voltammetry and SECM with Droplet Modified Electrode. Voltammetry and SECM were used as diagnostic tools to determine the mechanism of ion transfer reaction following $\mathrm{DMFc}^{+}$cation formation. This is an important aspect of the mechanism of $\mathrm{H}_{2} \mathrm{O}_{2}$ generation at ITIES. First, cyclic voltammetry was performed on GC electrode modified with droplet of DMFc solution in THxAP supported DCE immersed in a wide range of aqueous electrolytes, including these containing $\mathrm{ClO}_{4}^{-}$anions (Figure 1).

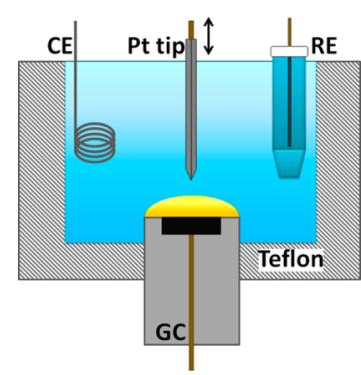

Figure 1. A scheme of the electrochemical cell used in the voltammetric and SECM measurements with droplet modified GC electrode.

The anodic and cathodic peaks on the voltammograms in Figure 2 are due to one electron oxidation of DMFc and reduction of $\mathrm{DMFc}^{+}$, respectively. It is clear that the position of voltammetric oxidation-reduction signal on the potential axis depends on the type of anion. Namely, the midpeak potential, $E_{\mathrm{mp}}$, is negatively shifted in the presence of more hydrophobic anions.

In order to maintain electroneutrality, reversible electrochemical oxidation of DMFc can be followed by anion insertion into DCE,

$$
\mathrm{DMFc}_{(\mathrm{DCE})}+\mathrm{An}_{(\mathrm{W})}^{-} \rightleftarrows \mathrm{DMFc}_{(\mathrm{DCE})}^{+}+\mathrm{An}_{(\mathrm{DCE})}^{-}+\mathrm{e}^{-}
$$

or organic electrolyte cation, $\mathrm{THxA}^{+}$, expulsion from DCE into the aqueous phase, 


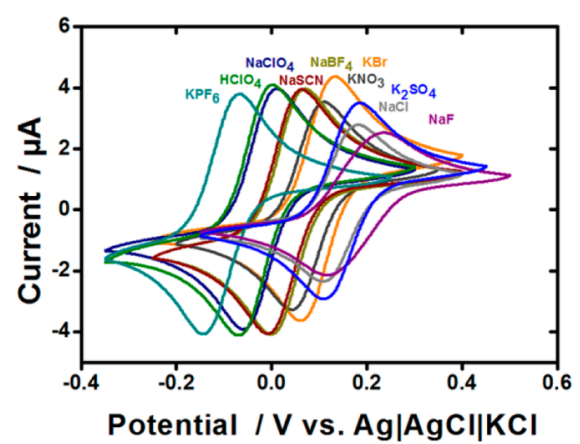

Figure 2. Cyclic voltammograms recorded at the GC electrode immersed in $0.1 \mathrm{~mol} \mathrm{dm}^{-3}$ aqueous solution of various salts. The GC electrode was covered with $2 \mu \mathrm{L}$ of $1 \mathrm{mmol} \mathrm{dm}^{-3}$ DMFc solution in $0.1 \mathrm{~mol} \mathrm{dm}^{-3}$ THxAP in DCE. Scan rate $=50 \mathrm{mV} \mathrm{s}^{-1}$.

$$
\begin{aligned}
& \mathrm{DMFc}_{(\mathrm{DCE})}+\mathrm{THxA}_{(\mathrm{DCE})}^{+} \\
& \rightleftarrows \mathrm{DMFc}_{(\mathrm{DCE})}^{+}+\mathrm{THxA}_{(\mathrm{W})}^{+}+\mathrm{e}^{-}
\end{aligned}
$$

or expulsion of newly formed $\mathrm{DMFc}^{+}$cation from DCE into the aqueous phase,

$$
\operatorname{DMFc}_{(\mathrm{DCE})} \rightleftarrows \mathrm{DMFc}_{(\mathrm{W})}^{+}+\mathrm{e}^{-}
$$

Almost constant magnitude of anodic and cathodic peak currents in the subsequent voltammetric scans is noted in the experiments performed in aqueous electrolyte containing $\mathrm{ClO}_{4}{ }^{-}$. This indicates no decrease of DMFc concentration in DCE deposit, pointing out reactions 4 or 5 . On the other hand, in the experiment performed in the aqueous $\mathrm{NaCl}$, as an example of an electrolyte with a more hydrophilic anion than $\mathrm{ClO}_{4}{ }^{-}$, a significant decrease of voltammetric current is seen (Supporting Information, Figure S2) indicating $\mathrm{DMFc}^{+}$ expulsion (reaction 6).

Here, as a diagnostic criterion for anion insertion reaction (reaction 4), the following Nernst type equation can be applied: ${ }^{16}$

$$
\begin{aligned}
E_{\mathrm{mp}}= & E_{\mathrm{DMFc}^{+} / \mathrm{DMFc}}^{\circ}+\Delta_{\mathrm{W}}^{\mathrm{DCE}} \phi_{\mathrm{An}^{-}}^{\circ}-\frac{R T}{F} \ln c_{\mathrm{An}^{-}(\mathrm{W})}+\frac{R T}{F} \\
& \ln \frac{c_{\mathrm{DMFc}}^{*}}{2}
\end{aligned}
$$

where $\Delta_{\mathrm{W}}^{\mathrm{DCE}} \phi_{\mathrm{An}^{-}}^{\circ}$ is the standard potential of anion transfer from $\mathrm{W}$ to $\mathrm{DCE}, c_{\mathrm{An}}{ }^{-}(\mathrm{W})$ is the concentration of anions in the aqueous phase, and $c_{\mathrm{DMFc}}^{*}$ is the concentration of DMFc in DCE. It predicts unity slope of $E_{\mathrm{mp}} \mathrm{vs} \Delta_{\mathrm{W}}^{\mathrm{DCE}} \phi_{\mathrm{An}^{-}}^{\circ}$ dependence if reaction 4 occurs, whereas zero slope is expected for reactions 5 and 6. Equation 7 also predicts $-59 \mathrm{mV} / \mathrm{dec}$ slope of logarithmic anion concentration dependence for reaction 4 . In the absence of anion insertion (reactions 5 and 6), zero slope is expected.

Here, for more hydrophobic anions linear dependence of $E_{\mathrm{mp}}$ vs $\Delta_{\mathrm{W}}^{\mathrm{DCE}} \phi_{\mathrm{An}}{ }^{-}$is seen with a slope of 0.6 (Figure 3 ). This effect is even more clear when a larger number of data is analyzed using literature values of standard transfer potentials for nitrobenzenelwater $\left(\Delta_{\mathrm{W}}^{\mathrm{NB}} \phi\right)$ systems (Supporting Information, Figure S1). Moreover, the slope of the dependence of the peak potential, $E_{\mathrm{p}}$ (obtained from SWV experiments), on the logarithm of $\mathrm{ClO}_{4}^{-}$concentration in the aqueous phase is equal to $-59 \mathrm{mV} / \mathrm{dec}$ These results, together with stability of voltammograms (Supporting Information, Figure S2) point to $\mathrm{ClO}_{4}{ }^{-}$insertion (reaction 4). The expulsion of $\mathrm{THxA}^{+}$cations

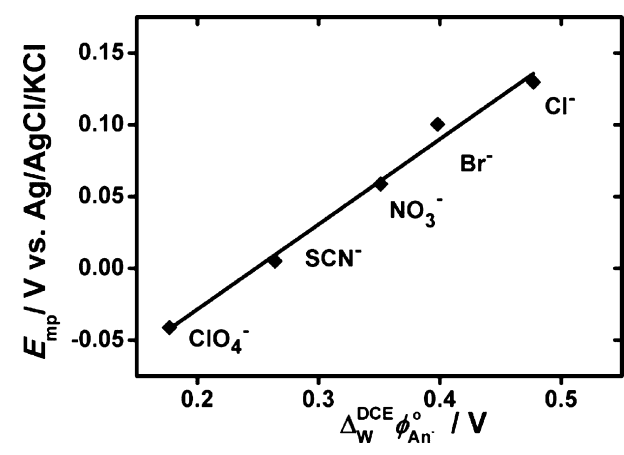

Figure 3. Dependence of the midpeak potential of the $\mathrm{DMFc}^{+} / \mathrm{DMFc}$ couple, $E_{\mathrm{mp}}$, on the standard transfer potential of the studied anions, $\Delta_{\mathrm{W}}^{\mathrm{DCE}} \phi_{\mathrm{An}^{-16}}{ }^{16}$ obtained from the data presented in Figure 2.

to aqueous solution can be ruled out because the transfer potential of $\mathrm{THxA}^{+}, \Delta_{\mathrm{W}}^{\mathrm{DCE}} \phi_{\mathrm{THxA}^{+}}^{\circ}=0.470 \mathrm{~V}^{28,29}$ is much higher than $\Delta_{\mathrm{W}}^{\mathrm{DCE}} \phi_{\mathrm{ClO}_{4}^{-}}^{\circ}=0.177 \mathrm{~V}$. $^{15}$

The slope of $-21 \mathrm{mV} / \mathrm{dec}$ of $E_{\mathrm{p}}$ vs logarithm of $\mathrm{Cl}^{-}$ concentration dependence indicates significant contribution of cation expulsion. The instability of voltammograms (Supporting Information, Figure S2) indicates that $\mathrm{DMFc}^{+}$is expelled from the DCE drop. However, similar values of transfer potential of $\mathrm{Cl}^{-}$anion $\left(\Delta_{\mathrm{W}}^{\mathrm{DCE}} \phi_{\mathrm{Cl}^{-}}^{\circ}=0.477 \mathrm{~V}^{15}\right)$ and $\mathrm{THxA}^{+}$ cation $\left(\Delta_{\mathrm{W}}^{\mathrm{DCE}} \phi_{\mathrm{THxA}^{+}}^{\circ}=0.470 \mathrm{~V}^{28,29}\right)$ indicate that $\mathrm{THA}^{+}$ expulsion is also likely to occur.

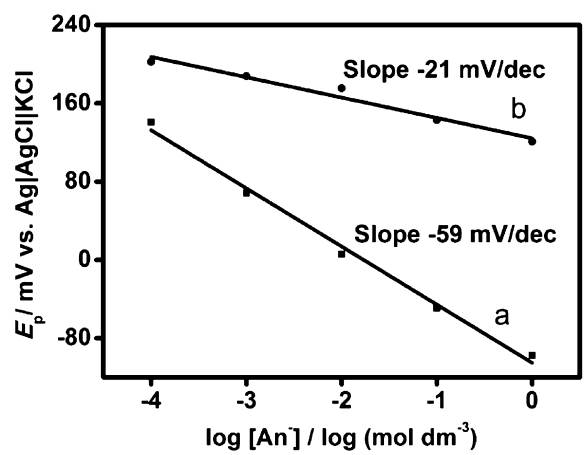

Figure 4. Dependence of the SWV peak potential of DMFc oxidation on the logarithm of $\mathrm{ClO}_{4}^{-}$(a) and $\mathrm{Cl}^{-}$(b) concentration in the aqueous phase. The SWV parameters: step potential $1 \mathrm{mV}$, frequency $8 \mathrm{~Hz}$, amplitude $50 \mathrm{mV}$.

In order to detect $\mathrm{DMFc}^{+}$cations expelled from DCE film, the SECM microelectrode tip (diameter $25 \mu \mathrm{m}$ ) was positioned in front of a liquid modified GC electrode to detect $\mathrm{DMFc}^{+}$ cations (Figure 1). ${ }^{30}$ The control of the distance between the tip and ITIES is a crucial point in this experiment. First, the approach curve to the liquid deposit was recorded by applying a potential of $0.2 \mathrm{~V}$ to the tip. This potential corresponds to oxidation of DMFc in DCE (Supporting Information, curves a and $b$ in Figure S3). The sharp increase of the current marks penetration of SECM tip into an organic phase ("enter point"). Then the tip movement direction was inverted, and at some position the current drops down indicating that the tip left the organic phase ("exit point") (Supporting Information, Figure S3). The distance between the "enter point" and "exit point' equals ca. $300 \mu \mathrm{m}$, perhaps due to hydrophobic DCE drop distortion caused by pushing and pulled out the hydrophilic SECM tip. However, one can assume that after retraction of the 
tip by the same distance from the "exit point" $(20 \mu \mathrm{m})$, the tipto-ITIES distance is always the same.

Then for $100 \mathrm{~s}$ potential $0.6 \mathrm{~V}$ was applied to DCE-modified $\mathrm{GC}$ electrode to produce $\mathrm{DMFc}^{+}$cations, whereas the SECM tip was kept at potential allowing for their reduction in aqueous phase $(-0.6 \mathrm{~V})$. Clearly, from cyclic voltammograms obtained at the tip after deposition, much higher anodic current, corresponding to oxidation of solid DMFc, ${ }^{31}$ is observed in aqueous $\mathrm{NaCl}$ than in $\mathrm{NaClO}_{4}$ (Figure 5), indicating more efficient expulsion of $\mathrm{DMFc}^{+}$cations in the presence of chloride ions.

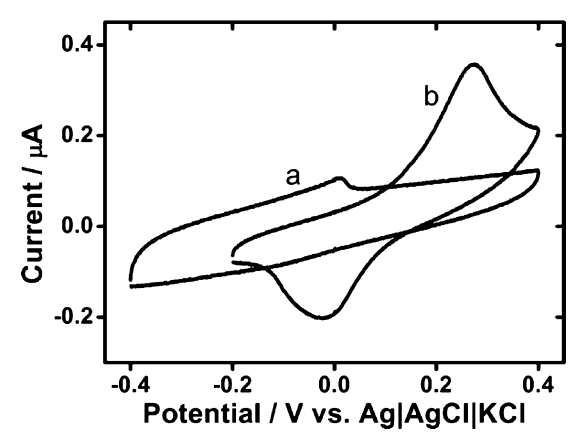

Figure 5. Cyclic voltammograms recorded at the $25 \mu \mathrm{m}$ diameter $\mathrm{Pt}$ microelectrode immersed in $0.1 \mathrm{~mol} \mathrm{dm}^{-3} \mathrm{NaClO}_{4}$ (a) or $\mathrm{NaCl}$ (b) aqueous solution after $100 \mathrm{~s}$ of deposition. The Pt electrode was placed in front of the GC electrode (Figure 1) coated with $30 \mu \mathrm{L}$ of 5

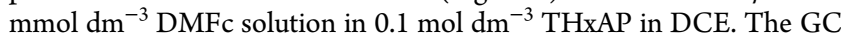
electrode potential was $0.6 \mathrm{~V}$. Scan rate $15 \mathrm{~V} \mathrm{~s}^{-1}$.

One can roughly estimate the concentration of $\mathrm{DMFc}^{+}$in the volume between the tip and organic phase $\left(C^{\circ}\right)$ from the following equation: ${ }^{32}$

$$
C^{\circ}=\frac{Q}{4 n F D r t}
$$

where $Q$ is the anodic peak charge integrated from $C V$ recorded after deposition, $n$ is the number of electrons transferred per molecule, $F$ is the Faraday constant, $D=1 \times$ $10^{-5} \mathrm{~cm}^{2} \mathrm{~s}^{-1}$ is the diffusion coefficient of $\mathrm{DMFc}^{+}$(its value was obtained in dichloromethane ${ }^{33}$ ), $r$ is the SECM tip radius, and $t$ is the time of electrolysis. ${ }^{32}$ This concentration is 1 order of magnitude smaller in aqueous $\mathrm{NaClO}_{4}$ solution $\left(2.1 \times 10^{-8}\right.$ mol dm $\left.{ }^{-3}\right)$ than in $\mathrm{NaCl}$ solution $\left(1.1 \times 10^{-7} \mathrm{~mol} \mathrm{dm}^{-3}\right)$ indicating a smaller contribution of $\mathrm{DMFc}^{+}$cation expulsion in the latter case.

To summarize, the experiments described above indicate that when DMFc solution in supported DCE is in contact with aqueous electrolyte containing $\mathrm{ClO}_{4}{ }^{-}$anions, oxidation of DMFc is followed by anion insertion from the aqueous to the organic phase.

$\mathrm{H}_{2} \mathrm{O}_{2}$ Generation at ITIES, Visual and Voltammetric Detection. Next, hydrogen peroxide generation at the polarized $\mathrm{DCE}(\mathrm{THxAP}) \mid \mathrm{W}\left(\mathrm{HClO}_{4}\right)$ interface was studied under aerobic conditions. The yellow solution of DMFc in DCE turns green after its oxidation, indicating formation of $\mathrm{DMFc}^{+}$cations. ${ }^{4,6}$ This is clearly visible after $24 \mathrm{~h}$ with different concentrations of DMFc or protons (Figure $6 \mathrm{~A}$, row II). In turn, violet color (Figure 6A, row IV) is seen when $\mathrm{KI}$ and starch are added to the aqueous phase, due to the following reaction: ${ }^{6}$

$$
3 \mathrm{I}^{-}+\mathrm{H}_{2} \mathrm{O}_{2}+2 \mathrm{H}^{+} \rightarrow \mathrm{I}_{3}^{-}+2 \mathrm{H}_{2} \mathrm{O}
$$

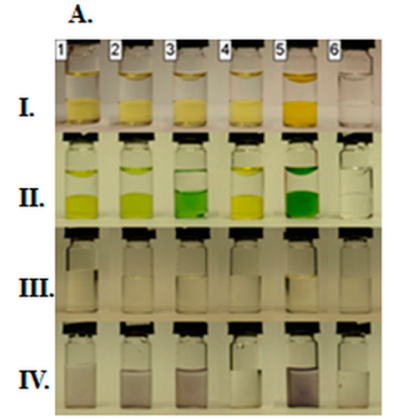

B.

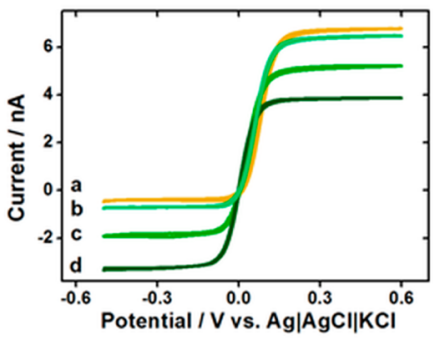

Figure 6. (A) Photographs of the reaction flasks just after solution preparation (row I) and after $24 \mathrm{~h}$ of two-phase reaction (row II), of aqueous phase collected after $24 \mathrm{~h}$ of two-phase reaction, mixed with 1 $\mathrm{mL}$ of $0.1 \mathrm{~mol} \mathrm{dm}^{-3}$ aqueous KI (row III) and of flasks from row III with $100 \mu \mathrm{L}$ of $10 \%$ starch solution added (row IV). Upper phase (rows I and II) consists of aqueous $\mathrm{HClO}_{4}\left(1,0.01 \mathrm{~mol} \mathrm{dm}^{-3} ; 2,0.1\right.$ mol dm${ }^{-3} ; 3,5$, and $\left.6,0.5 \mathrm{~mol} \mathrm{dm}{ }^{-3}\right)$ or $0.5 \mathrm{~mol} \mathrm{dm}^{-3} \mathrm{NaClO}_{4}(4$, control experiment). The lower phase contains various concentrations of DMFc in $0.1 \mathrm{~mol} \mathrm{dm}^{-3}$ THxAP solution in DCE $(1-4,5 \mathrm{mmol}$ $\left.\mathrm{dm}^{-3}, 5,50 \mathrm{mmol} \mathrm{dm}{ }^{-3}\right)$. Flasks in column 6 did not contain DMFc (control experiment). (B) Voltammograms recorded in the organic phase at a Pt microelectrode $(10 \mu \mathrm{m}$ diam $)$ immersed in fresh $5 \mathrm{mmol}$ $\mathrm{dm}^{-3}$ DMFc in $0.1 \mathrm{~mol} \mathrm{dm}{ }^{-3}$ THxAP solution in DCE (a) and after contact with 0.01 (b), 0.1 (c), and 0.5 (d) $\mathrm{mol} \mathrm{dm}^{-3} \mathrm{HClO}_{4}$ for $24 \mathrm{~h}$ in aerobic conditions. Scan rate was $20 \mathrm{mV} \mathrm{s}^{-1}$.

These results indicate a similar effect of electron donor and proton concentration on $\mathrm{H}_{2} \mathrm{O}_{2}$ generation rate. Results of control experiments with sodium perchlorate solution or in the absence of DMFc (Figure 6A, columns 4 and 6) indicate that both protons and electron donor are indispensable for this reaction. The reaction is slower than reported earlier under conditions favoring proton transfer across the liquidlliquid interface. ${ }^{6}$ As was shown above, $\mathrm{DMFc}^{+}$transfer into the aqueous phase is also minor. Taking into account that the value of $\Delta_{\mathrm{W}}^{\mathrm{DCE}} \phi_{\mathrm{ClO}_{4}^{-}}^{\circ}$ is higher than $\Delta_{\mathrm{W}}^{\mathrm{DCE}} \phi_{\mathrm{THxA}^{+}}^{\circ}=0.470 \mathrm{~V}^{28,29}$ and ${ }_{\mathrm{W}}^{\mathrm{DCE}} \phi_{\mathrm{H}^{+}}^{\circ}=-0.55 \mathrm{~V},{ }^{14}$ one can conclude that $\mathrm{H}_{2} \mathrm{O}_{2}$ generation occurs at the liquidlliquid interface and is accompanied by insertion of $\mathrm{ClO}_{4}^{-}$anions into the organic phase:

$$
\begin{aligned}
& \mathrm{O}_{2}+\operatorname{DMFc}(\mathrm{DCE})+2 \mathrm{H}_{(\mathrm{W})}^{+}+\mathrm{CLO}_{4}^{-}(\mathrm{w}) \\
& \rightarrow \mathrm{H}_{2} \mathrm{O}_{2(\mathrm{~W})}+\mathrm{DMFc}_{(\mathrm{DCE})}^{+}+\mathrm{CLO}_{4}^{-}{ }_{(\mathrm{DCE})}
\end{aligned}
$$

The role of the protons in reaction 10 is also confirmed by cyclic voltammetry in the organic phase after $24 \mathrm{~h}$ of reaction (Figure 6B). After contact with the organic phase, the cathodic wave corresponding to $\mathrm{DMFc}^{+}$cation electroreduction appears and its magnitude increases for a larger concentration of $\mathrm{HClO}_{4}$.

Spectroscopic Detection of $\mathrm{H}_{2} \mathrm{O}_{2}$. Concentration of $\mathrm{H}_{2} \mathrm{O}_{2}$ generated in the two-phase reaction was estimated by $\mathrm{UV}$-vis spectroscopy after separation of the aqueous phase. For this purpose, HRP-catalyzed reduction of hydrogen peroxide to water in the presence of $\mathrm{ABTS}^{2-}$ anion resulting in formation of $\mathrm{ABTS}^{\bullet-}$ anion radical, ${ }^{34}$

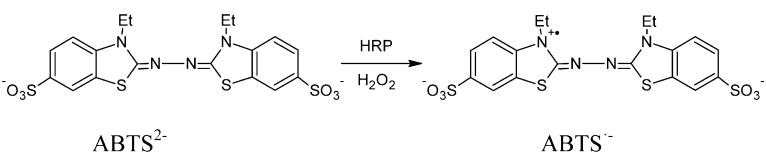

was employed. The reduced form of mediator exhibits characteristic absorption bands at 416 and $736 \mathrm{~nm}$ at $\mathrm{pH} 7$ 
(Supporting Information, Figure S4). Here, a calibration curve was constructed with acidic solution prepared by mixing $1.4 \mathrm{~mL}$ of $0.5 \mathrm{~g} \mathrm{dm}^{-3} \mathrm{HRP}$ and $1.82 \mathrm{mmol} \mathrm{dm} \mathrm{m}^{-3}\left(\mathrm{NH}_{4}\right)_{2} \mathrm{ABTS}$ solution in $0.1 \mathrm{~mol} \mathrm{dm}^{-3}$ phosphate buffer $(\mathrm{pH} 7)$ with $0.6 \mathrm{~mL}$ of 0.5 mol dm ${ }^{-3}$ aqueous $\mathrm{HClO}_{4}$ to keep similar amount of acid as in the flask experiments. A linear dependence of absorbance on concentration was found for $\mathrm{H}_{2} \mathrm{O}_{2}$ concentration range 0-30 mmol dm${ }^{-3}$ (Supporting Information, Figure S5). The two phase reaction was performed for $24 \mathrm{~h}$ in a glass flask $(13 \mathrm{~mm}$ inner diameter) with mechanical stirring after mixing $1.5 \mathrm{~mL}$ of 0.5 or $5 \mathrm{mmol} \mathrm{dm}{ }^{-3}$ DMFc with $0.1 \mathrm{~mol} \mathrm{dm}^{-3}$ THxAP in DCE and $1.5 \mathrm{~mL}$ of $0.5 \mathrm{~mol} \mathrm{dm}^{-3} \mathrm{HClO}_{4}$ under aerobic conditions. After addition of $\left(\mathrm{NH}_{4}\right)_{2} \mathrm{ABTS}$ and $\mathrm{HRP}$ to $0.6 \mathrm{~mL}$ of separated aqueous phase, the $\mathrm{H}_{2} \mathrm{O}_{2}$ concentration was determined as equal to 15 and $81 \mu \mathrm{mol} \mathrm{dm}{ }^{-3}$ for smaller and larger DMFc concentration, respectively. This is smaller than reported earlier under conditions favorable for proton transfer. ${ }^{6}$

SECM Enzymatic Detection of $\mathrm{H}_{2} \mathrm{O}_{2}$ at ITIES. Color change caused by mediator reduction can be also observed under quiescent conditions in the biphasic system (Figure 7).

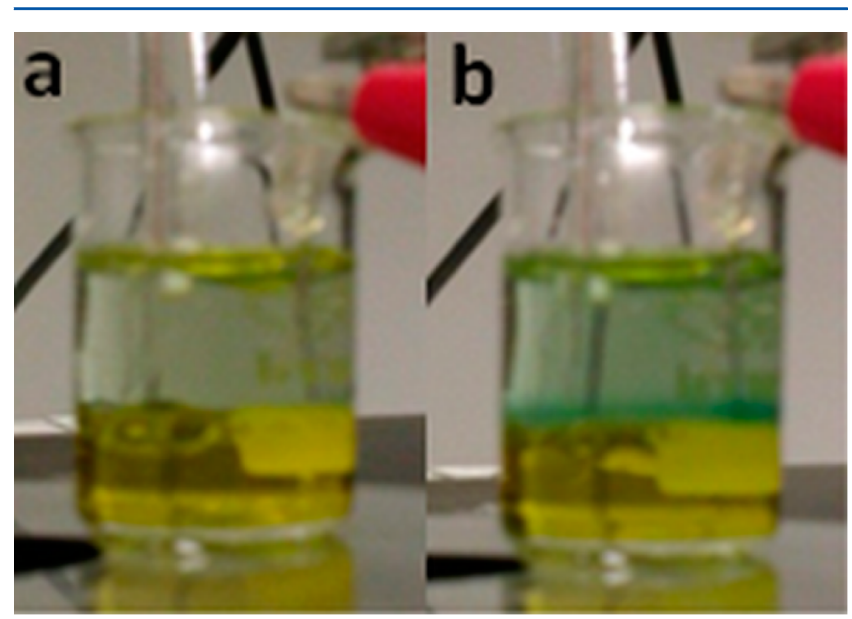

Figure 7. Photos of biphasic systems consisting of $50 \mathrm{mmol} \mathrm{dm}^{-3}$ DMFc in $0.1 \mathrm{~mol} \mathrm{dm}^{-3}$ THxAP in DCE (lower phase) and $0.5 \mathrm{~g} \mathrm{dm}^{-3}$ $\mathrm{HRP}, 1.82 \mathrm{mmol} \mathrm{dm}^{-3}\left(\mathrm{NH}_{4}\right)_{2} \mathrm{ABTS}$ in $0.1 \mathrm{~mol} \mathrm{dm}^{-3}$ aqueous $\mathrm{HClO}_{4}$ (upper phase) just after pouring solutions into the beaker (a) and 30 min later (b).

At the beginning of the experiment, the aqueous phase is slightly green perhaps due to oxidation of some $\mathrm{ABTS}^{2-}$ anions by dissolved oxygen. Thirty minutes later intensive green color appears near the ITIES indicating formation of ABTS ${ }^{\bullet-}$ in the aqueous phase close to the liquidlliquid interface. This also shows that HRP is still active at $\mathrm{pH} 1$, which has not been reported earlier. The control experiments in the absence of enzyme do not show any color change near the interface. This excludes the hypothesis about direct oxidation of $\mathrm{ABTS}^{2-}$ by $\mathrm{DMFc}^{+}$.

The generation of $\mathrm{H}_{2} \mathrm{O}_{2}$ next to the liquidlliquid interface was also detected by SECM with the same aqueous phase composition employing electroreduction of $\mathrm{ABTS}^{\bullet-}$ generated at ITIES at the tip (Figure 8A). When it is kept at $0.35 \mathrm{~V}$, $\mathrm{ABTS}^{\bullet-}$ is reduced (Figure S6 in Supporting Information). Therefore, the cathodic tip current increase seen during its approach to liquidlliquid interface (Figure 8B) confirms $\mathrm{H}_{2} \mathrm{O}_{2}$ generation. We made also an attempt to estimate its flux assuming fast kinetics of enzymatic reaction 12 (rate constant equals $10^{7} \mathrm{~mol}^{-1} \mathrm{dm}^{3} \mathrm{~s}^{-135}$ ). Under such conditions, $\mathrm{H}_{2} \mathrm{O}_{2}$ is converted to $\mathrm{H}_{2} \mathrm{O}$ immediately after its generation at the ITIES. Then, $\mathrm{ABTS}^{\bullet-}$ radical anions are generated only in the close vicinity to the interface (surface reaction) and they diffuse linearly from the interface at the same rate that they are generated at steady-state conditions. Concentration gradient of $\mathrm{ABTS}^{\bullet-}$ close to ITIES is then proportional to its flux according to the first Fick's law. The approach curve slope ( $\partial i$ / $\partial z$ ), obtained for distances higher than 10 radii of the SECM probe, where feedback effect ${ }^{20}$ is excluded, is equal to $152 \mathrm{pA}$ $\mathrm{cm}^{-1}$. It is proportional to the concentration gradient of $\mathrm{ABTS}^{\bullet-}$ and corresponds to the flux of $\mathrm{ABTS}^{\bullet-}, 3.15 \times 10^{-13}$ $\mathrm{mol} \mathrm{cm} \mathrm{cm}^{-2} \mathrm{~s}^{-1}$, according to the following equation:

$$
J_{\mathrm{ABTS}^{\cdot-}}=\left(\frac{\partial i}{\partial z}\right)\left(\frac{1}{4 n F r}\right)
$$

where $i$ is the current and $z$ is the SECM probe vertical position. According to the stoichiometry of the process (Figure $8 \mathrm{~A}$ ), the flux of $\mathrm{H}_{2} \mathrm{O}_{2}$ is half of the flux of $\mathrm{ABTS}^{\bullet-}$, that is, 1.58 $\times 10^{-13} \mathrm{~mol} \mathrm{~cm}^{-2} \mathrm{~s}^{-1}$.

It has to be emphasized that both methods of $\mathrm{H}_{2} \mathrm{O}_{2}$ detection are not much affected by its partitioning to DCE phase. $^{6}$

Regeneration of DMFc Electron Donor. $\mathrm{H}_{2} \mathrm{O}_{2}$ generation occurs only when the substrates $\left(\mathrm{O}_{2}\right.$ and protons $)$ and electron donor, $\mathrm{DMFc}$, meet at liquidlliquid interface. It seems that the efficiency of this process can be increased by electrochemical regeneration (reduction) of its oxidized form,
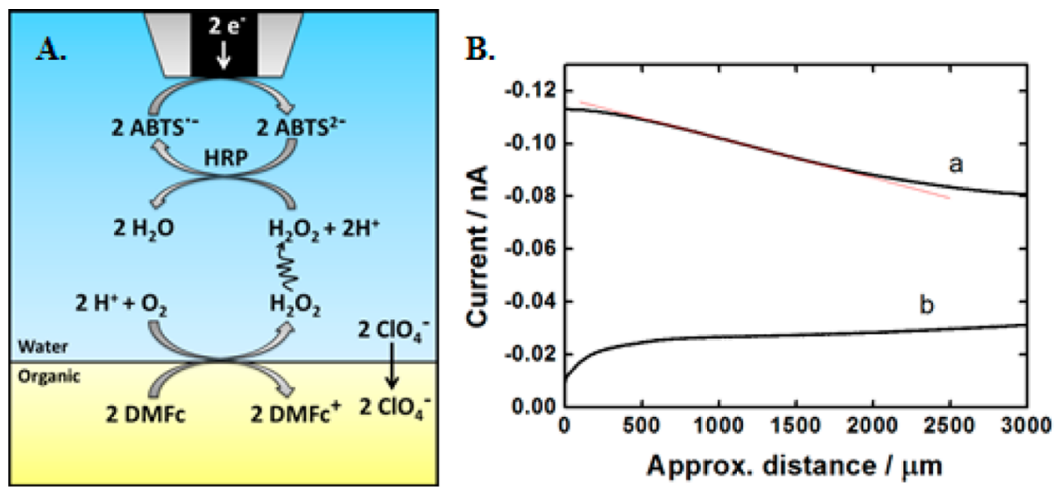

Figure 8. (A) Scheme of SECM experiment for enzymatic detection of $\mathrm{H}_{2} \mathrm{O}_{2}$ generated at the liquidlliquid interface. (B) Probe approach curves in the same system as shown in panel A and Figure 7 recorded in the presence (a) and absence (b) of HRP. Tip potential (Pt, $25 \mu \mathrm{m}$ diameter) was $0.35 \mathrm{~V}$, and its velocity was $10 \mu \mathrm{m} \mathrm{s}^{-1}$. 
$\mathrm{DMFc}^{+}$. In order to check whether it is possible, the SECM experiment was carried out with two microelectrodes of relatively large diameter $(100 \mu \mathrm{m}, \mathrm{Pt})$ facing each other on both sides of the liquidlliquid interface (Figure 9; Supporting Information, Figure S7).

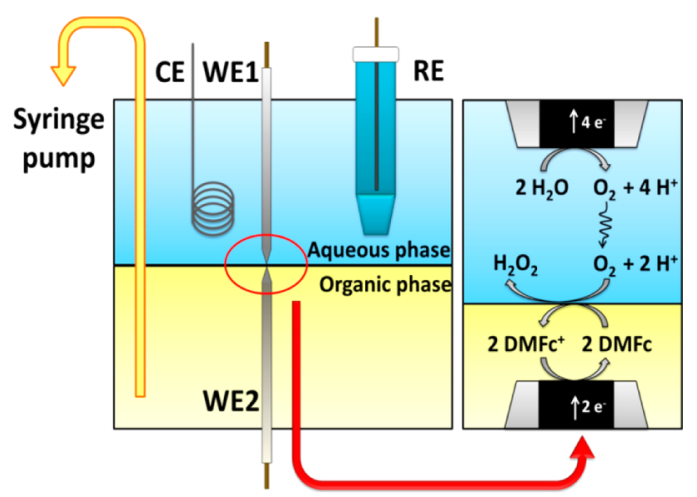

Figure 9. Scheme of the electrochemical cell used for SECM experiment with two microelectrodes close to the liquidlliquid interface.

When microelectrodes are present in separate phases far from the liquidlliquid interface, the voltammogram obtained with WE1 is typical for a platinum electrode in acidic aqueous solution with a characteristic anodic current increase at potentials higher than $1.4 \mathrm{~V}$ (Supporting Information, Figure S8), due to water oxidation to $\mathrm{O}_{2}$. The sigmoidal voltammogram resulting from the redox process of DMFc (Supporting Information, Figure S9) is seen on WE2 immersed in the organic phase, and the half-wave potential of the DMFc/ $\mathrm{DMFc}^{+}$couple was determined to be $-0.08 \mathrm{~V}$.

Precise positioning of microelectrodes with respect to ITIES is a crucial point for this experiment. First, in the absence of liquids, fronts of both electrodes were set at almost zero distance with a horizontally aligned optical microscope. Then the WE1 was retracted with exactly known distance (few millimeters), and the cell was filled with DCE electrolyte solution until WE2 was covered. Next, acidic aqueous electrolyte was added. With a syringe pump, the position of the ITIES was set at ca. $66 \mu \mathrm{m}$ above the WE2 microelectrode utilizing negative feedback of DMFc oxidation under conditions assuring diffusion limiting current ${ }^{19}$ (WE2 potential $0.15 \mathrm{~V}$ ). The liquid interface, hindering DMFc diffusion, was slowly lowered by sucking out the organic phase at a constant flow rate, and the current was recorded (Figure 10). Clearly, it decreases as the distance between WE2 and ITIES decreases. Then the distance was calculated using an equation developed by Cornut and Lefrou ${ }^{36}$ (see Supporting Information for details). At $t>300 \mathrm{~s}$, the pump was stopped, and ITIES was no longer descending. As a result, steady state current was recorded (Figure 10). This experiment shows that by using a simple stepper motor syringe pump and a syringe with piston diameter much smaller than that of the cell, one can control the position of soft interfaces such as ITIES.

The experimental normalized current $\left(I_{\mathrm{T}}\right)$ was calculated as 0.7 from the ratio of the currents recorded at the end and the beginning of experiment. Taking into account the ratio of the insulating glass sheath radius to the radius of the electrode (RG), equal to 4 , and the value of normalized heterogeneous rate constant $\kappa$, close to $0\left(10^{-9}\right)$, the distance between the

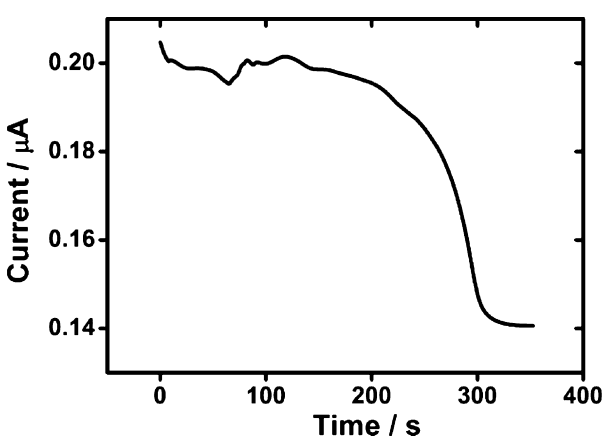

Figure 10. Current-time dependence measured with WE2 electrode at $0.15 \mathrm{~V}$ during decreasing the level of organic phase in the cell with setup presented in Figure 9 and Supporting Information, Figure S6.

liquidlliquid interface and the front of microelectrode E2 was calculated to be $66 \mu \mathrm{m}$.

Then the WE1 electrode was moved back toward the WE2 electrode until the distance between microelectrodes reached $30 \mu \mathrm{m}$. The liquidlliquid interface was pushed a bit (ca. $36 \mu \mathrm{m}$ ) by WE1 in such a way that a thin aqueous layer was created on its surface as was earlier observed with a water-nitrobenzene system. ${ }^{37}$ The characteristic shape of the $\mathrm{CV}$ recorded in these conditions (Supporting Information, Figure S8) confirms that WE1 remained in the aqueous phase. This indicates that SECM scanning at $30 \mu \mathrm{m}$ WE1-WE2 distance without contact of glass-sealed (hydrophilic) WE2 present in the organic phase with aqueous phase is possible. Further decrease of this distance was impossible, perhaps because of vibrations of the liquidl liquid interface. SECM imaging was performed with current recording at both microelectrodes. The potential of WE1 was set to $1.65 \mathrm{~V}$ to produce $\mathrm{O}_{2}$ by $\mathrm{H}_{2} \mathrm{O}$ oxidation. ${ }^{38}$ When $\mathrm{O}_{2}$ reduction to $\mathrm{H}_{2} \mathrm{O}_{2}$ occurs at the liquidlliquid interface (reaction $10), \mathrm{DMFc}^{+}$is produced in the organic phase close to the WE1 surface. This cation is rereduced on WE2 polarized at $-0.3 \mathrm{~V}$. Clearly higher cathodic current indicating an excess of $\mathrm{DMFc}^{+}$ was recorded at WE2 when the WE1 tip generating oxygen scanned above WE2 (Figure 11).

This experiment clearly shows regeneration of the electron donor indicating that DMFc may act as a redox catalyst. To confirm that the cathodic current at WE2 is indeed due to reduction of $\mathrm{DMFc}^{+}$and not due to the reduction of dissolved $\mathrm{O}_{2}$, we performed a blank experiment without DMFc in DCE.

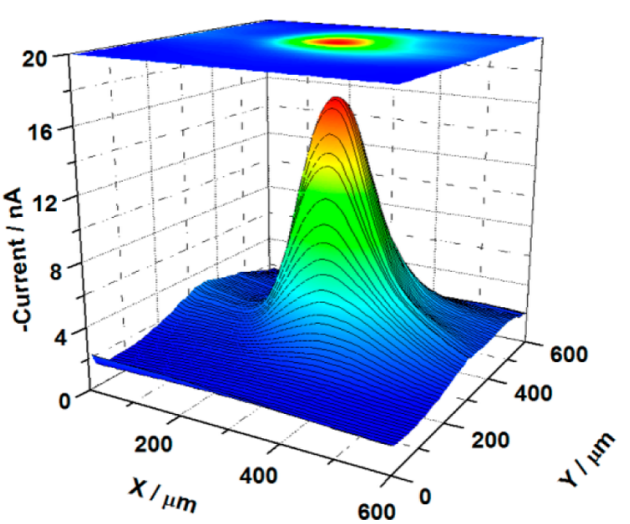

Figure 11. SECM image of $\mathrm{DMFc}^{+}$reduction at a $100 \mu \mathrm{m}$ diameter microelectrode in DCE phase. $\mathrm{DMFc}^{+}$was generated at ITIES by oxygen reduction. $\mathrm{O}_{2}$ was delivered by water electrolysis at scanning microelectrode. Scanning velocity: $20 \mu \mathrm{m} \mathrm{s}^{-1}$. See text for details. 
Negligible cathodic current indicates no contribution of the latter process, showing a crucial role of DMFc in ORR at the soft interface. Importantly, the collection efficiency, $\Theta=2 I_{\mathrm{S}} / I_{\mathrm{T}}$ (where $I_{\mathrm{s}}$ and $I_{\mathrm{T}}$ denote current recorded on WE2 and WE1, respectively, and the 2 factor is because generation of a single $\mathrm{O}_{2}$ molecule by water electrolysis requires four electrons contrary to two electrons required for its reduction to $\mathrm{H}_{2} \mathrm{O}_{2}$ ) depends on the tip position (Figure $\mathrm{S} 10$ in Supporting Information) in a similar way as the WE2 current (Figure 10).

\section{CONCLUSIONS}

This work shows that $\mathrm{H}_{2} \mathrm{O}_{2}$ can be successfully generated at ITIES polarized by $\mathrm{ClO}_{4}{ }^{-}$as a common ion in both phases. Under such conditions, proton transfer is unfavorable and twoelectron oxygen reduction occurs at the liquidlliquid interface. Although the reaction efficiency is smaller than in conditions favorable for proton transfer, ${ }^{1,3,4,6}$ this finding will allow us to use more available and less expensive electrolytes both in the organic and in the aqueous phase. Additionally, new methodology of $\mathrm{H}_{2} \mathrm{O}_{2}$ monitoring close to the liquidlliquid interface, based on scanning electrochemical microscopy and enzymatic reaction, was proposed. In our opinion, it can be applied to other interfaces such as solidlliquid interface. We also presented a method for increasing the efficiency of reaction by electrochemical regeneration of the electron donor. This gives new opportunities to reduce its amount as well as the volume of the organic phase, for example, droplets immobilized on the electrode surface ${ }^{16,39-41}$ where small amount of catalyst can be regenerated electrochemically.

\section{ASSOCIATED CONTENT}

\section{S Supporting Information}

Additional plots, voltammograms, spectra, and equations. This material is available free of charge via the Internet at http:// pubs.acs.org.

\section{AUTHOR INFORMATION}

\section{Corresponding Author}

*Mailing address: Institute of Physical Chemistry, Polish Academy of Sciences, Kasprzaka 44/52, 01-224 Warsaw, Poland. Telephone: +48343-7533. E-mail: mopallo@ichf.edu. pl.

\section{Author Contributions}

The manuscript was written through contributions of all authors. All authors have given approval to the final version of the manuscript.

\section{Notes}

The authors declare no competing financial interest.

\section{ACKNOWLEDGMENTS}

This research was supported by Polish-Swiss Research Programme, Project PSPB-035/2010: "Electrocatalysis at droplets". Wojciech Nogala acknowledges NanOtechnology Biomaterials and aLternative Energy Source for ERA Integration [FP7-REGPOT-CT-2011-285949-NOBLESSE] Project from European Union.

\section{REFERENCES}

(1) Mendez, M.; Partovi-Nia, R.; Hatay, I.; Su, B.; Ge, P.; Olaya, A.; Younan, N.; Hojeij, M.; Girault, H. Molecular electrocatalysis at soft interfaces. Phys. Chem. Chem. Phys. 2010, 12, 15163-15171.
(2) Volkov, A.; Deamer, D.; Tanelian, D.; Markin, V. Liquid Interfaces in Chemistry and Biology; Wiley: New York, 1998.

(3) Partovi-Nia, R.; Su, B.; Li, F.; Gros, C. P.; Barbe, J.-M.; Samec, Z.; Girault, H. Proton Pump for $\mathrm{O}_{2}$ Reduction Catalyzed by 5,10,15,20tetra- phenylporphyrinatocobalt(II). Chem.-Eur. J. 2009, 15, 23352340.

(4) Su, B.; Hatay, I.; Ge, P. Y.; Mendez, M.; Corminboeuf, C.; Samec, Z.; Ersoz, M.; Girault, H. Oxygen and proton reduction by decamethylferrocene in non-aqueous acidic media. Chem. Commun. 2010, 46, 2918-2919.

(5) Hage, R.; Lienke, A. Applications of Transition-Metal Catalysts to Textile and Wood-Pulp Bleaching. Angew. Chem., Int. Ed. 2006, 45, 206-222.

(6) Su, B.; Partovi-Nia, R.; Li, F.; Hojeij, M.; Prudent, M.; Corminboeuf, C.; Samec, Z.; Girault, H. $\mathrm{H}_{2} \mathrm{O}_{2}$ generation by decamethylferrocene at a liquidlliquid interface. Angew. Chem., Int. Ed. 2008, 47, 4675-4678.

(7) Cunnane, V.; Geblewicz, G.; Schiffrin, D. Electron and ion transfer potentials of ferrocene and derivatives at a liquidlliquid interface. J. Electrochim. Acta 1995, 40, 3005-3014.

(8) Trojanek, A.; Langmaier, J.; Su, B.; Girault, H.; Samec, Z. Electrochemical evidence of catalysis of oxygen reduction at the polarized liquid-liquid interface by tetraphenylporphyrin monoacid and diacid. Electrochem. Commun. 2009, 11, 1940-1943.

(9) Hatay, I.; Su, B.; Mendez, M.; Corminboeuf, C.; Khoury, T.; Gros, C.; Bourdillon, M.; Meyer, M.; Barbe, J.-M.; Ersoz, M.; Zalis, S.; Samec, Z.; Girault, H. Oxygen reduction catalyzed by a fluorinated tetraphenylporphyrin free base at liquid/liquid interfaces. J. Am. Chem. Soc. 2010, 132, 13733-13741.

(10) Su, B.; Hatay, I.; Trojanek, A.; Samec, Z.; Khoury, T.; Gros, C.; Barbe, J.-M.; Daina, A.; Carrupt, P.-A.; Girault, H. Molecular electrocatalysis for oxygen reduction by cobalt porphyrins adsorbed at liquid/liquid interfaces. J. Am. Chem. Soc. 2010, 132, 2655-2662.

(11) Trojánek, A.; Mareček, V.; Jänchenová, H.; Samec, Z Molecular electrocatalysis of the oxygen reduction at a polarized interface between two immiscible electrolyte solutions by $\mathrm{Co}(\mathrm{II})$ tetraphenylporphyrin. Electrochem. Commun. 2007, 9, 2185-2190.

(12) Hatay, I.; Su, B.; Li, F.; Mendez, M.; Khoury, T.; Gros, C.; Barbe, J.-M.; Ersoz, M.; Samec, Z.; Girault, H. Proton-coupled oxygen reduction at liquidlliquid interfaces catalyzed by cobalt porphine. J. Am. Chem. Soc. 2009, 131, 13453-13459.

(13) Ohde, H.; Maeda, K.; Yoshida, Y.; Kihara, S. Redox reactions between molecular oxygen and tetrachlorohydroquinone at the waterl 1,2-dichloroethane interface. J. Electroanal. Chem. 2000, 483, 108-116.

(14) Hatay, I.; Su, B.; Li, F.; Partovi-Nia, R.; Vrubel, H.; Hu, X.; Ersoz, M.; Girault, H. Hydrogen Evolution at Liquid-Liquid Interfaces. Angew. Chem., Int. Ed. 2009, 48, 5139-5142.

(15) Czapkiewicz, J.; Czapkiewicz-Tutaj, B. Relative Scale of Free Energy of Transfer of Anions. J. Chem. Soc., Faraday Trans. I 1980, 76, 1663-1668.

(16) Komorsky-Lovric, S.; Lovric, M.; Scholz, F. Cyclic voltammetry of decamethylferrocene at the organic liquid aqueous solution graphite three-phase junction. J. Electroanal. Chem. 2001, 508, 129-137.

(17) Kadnikova, E. N.; Kostic, N. Oxidation of ABTS by hydrogen peroxide catalyzed by horseradish peroxidase encapsulated into sol gel glass. Effects of glass matrix on reactivity. J. Mol. Catal. B: Enzym. 2002, 18, 39-48.

(18) Lindgren, A.; Ruzgas, T.; Gorton, L.; Csoregi, E.; Ardila, G.; Sakharov, I.; Gazaryan, I. Biosensors based on novel peroxidases with improved properties in direct and mediated electron transfer. Biosens. Bioelectron. 2000, 15, 491-497.

(19) Scanning Electrochemical Microscopy; Bard, A., Mirkin, M., Eds.; Taylor \& Francis Group: New York, 2012.

(20) Li, F.; Su, B.; Salazar, F.; Partovi-Nia, R.; Girault, H. Detection of hydrogen peroxide produced at a liquid/liquid interface using scanning electrochemical microscopy. Electrochem. Commun. 2009, 11, 473-476. 
(21) Morales, A.; Cespedes, F.; Munoz, J.; Martinez-Fabregas, E.; Alegret, S. Hydrogen peroxide amperometric biosensor based on a biocomposite. Anal. Chim. Acta 1996, 332, 131-138.

(22) Yu, J.; Ju, H. Preparation of porous titania sol-gel matrix for immobilization of horseradish peroxidase by a vapor deposition method. Anal. Chem. 2002, 74, 3579-3583.

(23) Cheng, X.; Challier, L.; Etcheberry, A.; Noel, V.; Perez, H. The ABTS-HRP System as an Alternative Method to RRDE for the Determination of the Selectivity of the Oxygen Reduction Reaction. Int. J. Electrochem. Sci. 2012, 7, 6247-6264.

(24) Childs, R.; Bardsley, W. The steady-state kinetics of peroxidase with 2,2'-azino-di-(3-ethyl-benzthiazoline-6-sulphonic acid) as chromogen. Biochem. J. 1975, 145, 93-103.

(25) Wang, Q.; Kromka, A.; Houdkova, J.; Babchenko, O.; Rezek, O.; Li, M.; Boukherroub, R.; Szunerits, S. Nanomolar Hydrogen Peroxide Detection Using Horseradish Peroxidase Covalently Linked to Undoped Nanocrystalline Diamond Surfaces. Langmuir 2012, 28, 587-592.

(26) Nogala, W.; Burchardt, M.; Opallo, M.; Rogalski, J.; Wittstock, G. Scanning electrochemical microscopy study of laccase within a solgel processed silicate film. Bioelectrochemistry 2008, 72, 174-182.

(27) House, H.; Feng, E.; Peet, N. Comparison of various tetraalkylammonium salts as supporting electrolytes in organic electrochemical reactions. J. Org. Chem. 1971, 36, 2371-2375.

(28) Antoine, J. P.; de Aguirre, I.; Janssens, F.; Thyrion, F. Aspects physicochimiques de la catalyse par transfert de phase. J. Bull. Soc. Chim. Fr. 1980, II, 207-232.

(29) Olaya, A.; Mendez, M.; Cortes-Salazar, F.; Girault, H. Voltammetric determination of extreme standard Gibbs ion transfer energy. J. Electroanal. Chem. 2010, 644, 60-66.

(30) Donten, M.; Stojek, Z.; Scholz, F. Electron transfer - ion insertion electrochemistry at an immobilized droplet: Probing the three-phase electrode-reaction zone with a Pt disk microelectrode. Electrochem. Commun. 2002, 4, 324-329.

(31) Bond, A.; Marken, F. Mechanistic aspects of the electron and ion transport processes across the electrode | solid | solvent (electrolyte) interface of microcrystalline decamethylferrocene attached mechanically to a graphite electrode. J. Electroanal. Chem. 1994, $372,125-135$.

(32) Shul, G.; Nogala, W.; Zakorchemna, I.; Niedziolka, J.; Opallo, M. Scanning electrochemical microscopy study of ion transfer process across water/2-nitrophenyloctylether interface supported by hydrophobic carbon ceramic electrode. J. Solid State Electrochem. 2008, 12, $1285-1291$.

(33) Goldfarb, D.; Corti, H. Steady-state voltammetric study of the reduction of decamethylferrocenium in dichloromethane at microelectrodes. J. Electroanal. Chem. 2001, 509, 155-162.

(34) Grotzky, A.; Nauser, T.; Erdogan, H.; Schluter, D.; Walde, P. A Fluorescently Labeled Dendronized Polymer-Enzyme Conjugate Carrying Multiple Copies of Two Different Types of Active Enzymes. J. Am. Chem. Soc. 2012, 134, 11392-11395.

(35) Smith, A.; Sanders, S.; Thorneley, R.; Burke, J.; Bray, R. Characterization of a haem active-site mutant of horseradish peroxidase, Phe $41 \rightarrow$ Val, with altered reactivity towards hydrogen peroxide and reducing substrates. Eur. J. Biochem. 1992, 207, 507-519.

(36) Cornut, R.; Lefrou, C. New analytical approximation of feedback approach curves with a microdisk SECM tip and irreversible kinetic reaction at the substrate. J. Electroanal. Chem. 2008, 621, 178-184.

(37) Barker, A.; Macpherson, J.; Slevin, C.; Unwin, P.. Scanning Electrochemical Microscopy (SECM) as a Probe of Transfer Processes in Two-Phase Systems: Theory and Experimental Applications of SECM-Induced Transfer with Arbitrary Partition Coefficients, Diffusion Coefficients, and Interfacial Kinetics. J. Phys. Chem. B 1998, 102, 1586-1598.

(38) Eckhard, K.; Schuhmann, W. Localized visualization of $\mathrm{O}_{2}$ consumption and $\mathrm{H}_{2} \mathrm{O}_{2}$ formation by means of SECM for the characterization of fuel cell catalyst activity. Electrochim. Acta 2007, 53, 1164-1169.
(39) Komorsky-Lovric, S.; Lovric, M.; Scholz, F. Square-Wave Voltammetry of Decamethylferrocene at the Three-Phase Junction Organic Liquid/Aqueous Solution/Graphite. Collect. Czech. Chem. Commun. 2001, 66, 434-444.

(40) Adamiak, W.; Opallo, M. Electrochemical redox processes of fullerene $\mathrm{C}_{60}$ and decamethylferrocene dissolved in cast 1,2dichlorobenzene film in contact with aqueous electrolyte. J. Electroanal. Chem. 2010, 643, 82-88.

(41) Quentel, F.; Mirceski, V.; L’Her, M.; Mladenov, M.; Scholz, F.; Elleouet, C. Comparative Study of the Thermodynamics and Kinetics of the Ion Transfer Across the LiquidlLiquid Interface by Means of Three-Phase Electrodes. J. Phys. Chem. B 2005, 109, 13228-13236. 